\title{
Water-Salt Metabolism in Rats with Acute Renal Failure Following Using Electrochemically Active Water Solutions
}

\author{
Aizman RI ${ }^{1,2 *}$, Koroshchenko GA ${ }^{1}$, Kozlova $\mathrm{AP}^{1}$ and Khachatryan $\mathrm{AA}^{3}$ \\ ${ }^{1}$ Department of Human Anatomy, Physiology and Safety of Life, Russia \\ ${ }^{2}$ Novosibirsk Research Institute of Hygiene, Russia \\ ${ }^{3}$ International Academy of Health, Russia
}

*Corresponding author: Aizman RI, Department of Human Anatomy, Physiology and Safety of Life, Russia.

Received Date: August 15, 2019

Published Date: August 29, 2019

\section{Introduction}

The importance of the kidney in maintaining and regulating the body's homeostasis can be understood when there is a violation of their functions due to pathology. One of the most serious complications of mechanical injury is impaired renal hemodynamics and necrotic changes in the nephrons, which cause acute renal failure (ARF), that leads to death in $58 \%$ of cases. In clinical practice, various methods and drugs are widely used to treat renal failure and its complications, however, the problem of developing and using new protectors occupies an important place in experimental and clinical nephrology [1].

Electro activation is a relatively new branch in medicine, which opens wide possibilities for using water solutions treated with electric current as medicines in experiments and in the clinic [2,3]. Electrochemically activated water solutions (EAS) are formed under a certain mode of electrical exposure in the anode or cathode chambers of diaphragm electrical installations [4]. Catholyte (EAS-K) increases the intensity of electrochemical processes, has anti-inflammatory and general tonic properties, normalizes the energy potential of cells and increases the intensity and efficiency of tissue respiration. Anolyte (EAS-A) has analgetic, anti-allergic, anti-inflammatory, antiseptic properties (antifungal, antiviral and antibacterial), that is explained by the high oxidizing properties of the solution and the content of chemical compounds that produce chlorine, oxygen and ozone [4].

\section{Aim}

In this regard, it was of interest to study the effects of the above electrically activated water solutions on renal functions during the development of acute renal failure.

\section{Methods}

To this end, we have provided an experiment on adult Wistar rats weighing 200-250 grams. All animals were divided into 2 groups. The first group consisted of intact animals of the control group ( $\mathrm{n}=36$ ), the second group - animals with an experimental model of acute renal failure (ARF) $(n=22)$. To simulate an acute renal failure, the animals were dehydrated for 24 hours before the start of the experiment. Then, 50\% glycerol solution was injected into the femoral muscles of both limbs at the volume of $1 \mathrm{ml} / 100$ $\mathrm{g}$ of body weight [5]. This procedure causes the ischemic injury of kidneys producing the model of ARF $[6,7]$.

To determine the effect of the EAS, each experimental group was divided into 3 subgroups: the first subgroup - animals that consumed tap water; the 2-nd subgroup - animals that used EAS-K; the 3-d subgroup - animals that consumed EAS-A. All animals were in standard vivarium conditions with free access to water and food. On day 6, animals were landed in metabolic cages to collect background urine samples. At the end of the experiment, blood samples were taken from the inferior vena cava for subsequent determination of ion-osmotic parameters, as well as liver, kidney, and femoral muscle tissue samples to determine the water content. Concentration of $\mathrm{Na}$ and $\mathrm{K}$ in plasma and urine was determined by plame photometry method (BWB-XP flame photometer, Great Britain), osmolality - by cryoscope method («Osmomat», Germany), creatinine and urea concentration - by biochemical analysis of the samples (analyzer «BS-200E», China); the water amount in tissues - as the difference between wet and dry mass of the samples. Partial renal functions were calculated according to generally accepted 
formulas [8]. The calculations were performed using the Microsoft Office software package. Statistical analysis was performed based on the calculation of arithmetic means $(M)$ and their errors $( \pm m)$. Differences between the parameters were evaluated by the method of variation statistics by the $\mathrm{t}$ - Student criterion and considered significant at $\mathrm{p} \leq 0.05$ [9].

\section{Results}

At the first stage of the study, an analysis of ion-osmotic parameters of rat blood plasma was carried out. It was found that in intact animal's various water solutions did not cause significant changes in the concentration of ions and osmolality, except for a significant decrease in urea in plasma after intake of EAS-A. In rats with ARF, the concentration of sodium and potassium practically did not change following EAS intake, while in rats consuming water $\mathrm{P}_{\mathrm{Na}}$ and $\mathrm{P}_{\mathrm{k}}$ had tendency or significantly decreased. The level of creatinine and urea in ARF rats was significantly higher than the corresponding indices of healthy animals. The changes obtained may indicate a violation of the functional state of the kidneys and the development of renal failure [1]. At the same time, no significant differences were found among animals that received different electrochemically activated water solutions, although after EAS-A there was a tendency to lower plasma urea concentration compare to EAS-K (Table 1).

Table 1: Plasma ion- osmotic parameters in rats $(\mathrm{M} \pm \mathrm{m})$

\begin{tabular}{|c|c|c|c|c|c|c|}
\hline \multirow{2}{*}{ Parameter, mM/L } & \multicolumn{3}{|c|}{ Control } & \multicolumn{2}{c|}{ ARF } \\
\cline { 2 - 7 } & Water & EAS-A & EAS-K & Water & EAS-A & EAS-K \\
\hline $\mathrm{P}_{\mathrm{Na}}$ & $139,4 \pm 3,5$ & $138,3 \pm 2,1$ & $139,7 \pm 3,0$ & $127,4 \pm 3,6$ & $141,6 \pm 2,1$ & $138,9 \pm 2,1^{\mathbf{\Delta}}$ \\
\hline $\mathrm{P}_{\mathrm{K}}$ & $4,1 \pm 0,2$ & $3,9 \pm 0,2$ & $4,0 \pm 0,3$ & $3,1 \pm 0,4^{*}$ & $3,7 \pm 0,6$ & $4,1 \pm 0,95$ \\
\hline $\mathrm{P}_{\text {creat }}$ & $1,14 \pm 0,04$ & $1,11 \pm 0,05$ & $1,09 \pm 0,02$ & $1,5 \pm 0,03^{*}$ & $1,5 \pm 0,07^{*}$ & $1,6 \pm 0,08^{*}$ \\
\hline $\mathrm{P}_{\text {urea }}$ & $54,0 \pm 4,9$ & $33,8 \pm 5,6^{\mathbf{\Delta}}$ & $49,8 \pm 4,8$ & $100,1 \pm 16,2^{*}$ & $85,1 \pm 12,2^{*}$ & $124,9 \pm 24,6^{*}$ \\
\hline $\mathrm{P}_{\text {osm. }}$ & $293,4 \pm 3,2$ & $290,2 \pm 4,1$ & $296,7 \pm 5,7$ & $286,4 \pm 5,2$ & $297,1 \pm 4,5$ & $294,4 \pm 4,9$ \\
\hline
\end{tabular}

Note: * - significant differences from similar control parameters $(p \leq 0.05)$;

$\Delta$ - significant differences between the experimental groups (catholyte, anolyte) $(p \leq 0.05)$;

$\Delta$ - significant differences compared with the water group $(p \leq 0.05)$

Thus, we can conclude that in healthy animals electrochemically active solutions did not cause significant changes in the ion-osmotic parameters of blood plasma, while in rats with experimental model of ARF it reduced ion shifts, especially following EAS-A intake. A study of the hydrouretic renal function revealed an increase in the level of diuresis in rats with acute renal failure compare to control animals, both anolyte and catholyte intake did not affect significantly the urine excretion (Table 2). The obtained polyuretic effect can be explained by a decrease in the level of tubular reabsorption in these groups compared to the control, while GFR was significantly lower

Table 2: Hydro- and ionuretic renal functions in rats $(\mathrm{M} \pm \mathrm{m})$ than in untact rats. EAS-A slightly stimulated the GFR in comparison with water and EAS-K intake. Analysis of the ion-uretic function showed an increase in the level of renal potassium excretion in animals with acute renal failure, which coincides with published data and may be additional evidence of the development of renal failure [1]. The decrease in filtration and reabsorption processes in rats with acute renal failure was accompanied by a significant increase in the excreted sodium and potassium fractions. In experimental animals treated with EAS-A, the excreted potassium fraction was lower than in animals received water and EAS-K.

\begin{tabular}{|c|c|c|c|c|c|c|}
\hline \multirow{2}{*}{ Parameter } & \multicolumn{3}{|c|}{ Control } & \multicolumn{2}{c|}{ ARF } \\
\cline { 2 - 6 } & Water & EAS-A & EAS-K & Water & EAS-A & EAS-K \\
\hline $\mathrm{V}, \mathrm{ml} / 100 \mathrm{~g}^{*} \mathrm{~h}$ & $0,05 \pm 0,02$ & $0,03 \pm 0,01$ & $0,04 \pm 0,01$ & $0,15 \pm 0,05$ & $0,17 \pm 0,03^{*}$ & $0,12 \pm 0,03^{*}$ \\
\hline $\mathrm{GFR}, \mathrm{ml} / 100 \mathrm{~g} * \mathrm{~h}$ & $13,7 \pm 3,4$ & $20,6 \pm 2,12$ & $12,2 \pm 2,5^{\Delta}$ & $10,4 \pm 1,1$ & $13,9 \pm 0,8^{* \boldsymbol{\Delta}}$ & $6,6 \pm 0,8^{* \mathbf{\Delta} \Delta}$ \\
\hline $\mathrm{R}_{\mathrm{H} 20^{\prime}} \%$ & $99,6 \pm 0,1$ & $99,7 \pm 0,03$ & $99,6 \pm 0,09$ & $98,9 \pm 0,5$ & $98,6 \pm 0,2^{*}$ & $98,8 \pm 0,3^{*}$ \\
\hline $\mathrm{U}_{\mathrm{Na}}{ }^{*} \mathrm{~V}, \mathrm{mcM} / 100 \mathrm{~g} * \mathrm{~h}$ & $4,0 \pm 1,5$ & $13,7 \pm 0,6 \mathbf{\Delta} \Delta$ & $7,0 \pm 2,8$ & $16,9 \pm 7,2$ & $10,7 \pm 3,9$ & $19,8 \pm 6,2$ \\
\hline $\mathrm{U}_{\mathrm{K}}{ }^{*} \mathrm{~V}, \mathrm{mcM} / 100 \mathrm{~g}^{*} \mathrm{~h}$ & $15,6 \pm 6,4$ & $12,0 \pm 1,5$ & $8,9 \pm 3,1$ & $37,2 \pm 4,7^{*}$ & $24,3 \pm 5,1^{*}$ & $27,1 \pm 9,7$ \\
\hline $\mathrm{EF}_{\mathrm{Na}^{\prime}} \%$ & $0,2 \pm 0,1$ & $0,4 \pm 0,05$ & $0,4 \pm 0,2$ & $1,8 \pm 0,8$ & $1,6 \pm 0,3^{*}$ & $2,7 \pm 0,5^{*}$ \\
\hline $\mathrm{EF}_{\mathrm{K}^{\prime}} \%$ & $22,8 \pm 10,2$ & $15,03 \pm 3,3$ & $13,06 \pm 2,8$ & $102,3 \pm 17,5^{*}$ & $55,9 \pm 12,0^{* \boldsymbol{\Delta}}$ & $98,9 \pm 17,8^{*}$ \\
\hline
\end{tabular}

Note: * - significant differences from similar control parameters $(p \leq 0.05)$;

$\Delta$ - significant differences between the experimental groups (catholyte, anolyte) $(p \leq 0.05)$;

$\Delta$ - significant differences compared with the water group $(p \leq 0.05)$

These data indicate that EAS-A contributes slightly to normalize diuretic and ionuretic renal functions in rats with ARF compare to water and EAS-K intake. Analyzing the state of tissue water-salt depots, it should be noted that taking anolyte and catholyte did not cause significant changes in the content of water both in healthy animals and in rats with acute renal failure. Only a significant increase in the percentage of water content in the renal tissue and tendency to elevation in sceletal muscles during acute renal failure were recorded in all rat groups compared with control animals (Table 3). 
Table 3: The water content in rat's organs water-salt depot (\%)

\begin{tabular}{|c|c|c|c|c|c|c|}
\hline \multirow{2}{*}{ Organ } & \multicolumn{3}{|c|}{ Control } & \multicolumn{2}{c|}{ ARF } \\
\cline { 2 - 7 } & Water & EAS-A & EAS-K & Water & EAS-A & EAS-K \\
\hline Liver & $67,8 \pm 1,3$ & $66,9 \pm 0,9$ & $67,1 \pm 0,7$ & $69,0 \pm 0,8$ & $69,0 \pm 0,6$ & $68,9 \pm 1,3$ \\
\hline Kidney & $72,3 \pm 0,9$ & $73,5 \pm 0,7$ & $74,1 \pm 0,4$ & $77,6 \pm 1,1^{*}$ & $78,6 \pm 0,4^{*}$ & $77,6 \pm 0,5^{*}$ \\
\hline Sceletal muscle & $71,6 \pm 1,6$ & $73,0 \pm 1,7$ & $71,6 \pm 1,6$ & $76,4 \pm 1,2^{*}$ & $76,4 \pm 0,3$ & $74,9 \pm 1,4$ \\
\hline
\end{tabular}

Note: * - significant differences from similar control parameters $(p \leq 0.05)$;

$\Delta$ - significant differences between the experimental groups (catholyte, anolyte) $(p \leq 0.05)$;

$\Delta$ - significant differences compared with the water group $(p \leq 0.05)$

\section{Conclusion}

Thus, the intake of electrochemically activated water solutions did not cause significant changes in the functions of the kidneys and water-salt metabolism both in healthy animals and rats with acute renal failure. The tendency to improve the hydro- and ionuretic renal functions in ARF rats following intake of EAS-A compare to water and EAS-K can be only noted. These mechanisms of renal changes in rats with ARF after consumption of EAS-solutions require further analysis.

\section{Acknowledgement}

None.

\section{Conflict of Interest}

No conflict of interest.

\section{References}

1. Karder, Basel (2007) Acute kidney injury. In: Kellum JA, Bellomo R, Ronco C (eds), Contributions to nephrology, pp. 464.
2. Zarezaev OA, Korneva TK, Panicheva SA (1994) Treatment of the surgeon's hands with electrochemical activated solutions and microbiological control of the method. Electrochemical activation in medicine, agriculture, industry, Russia, pp. 88-91.

3. Dobriyanets AI, Zhidkov SA, Kuzmin Yu V (2000) Method of indirect electrochemical detoxification of the body using sodium hypochlorite in practical medicine: Methodological recommendations, Europe, pp. 26.

4. Academy of Medical and Technical Sciences of the Russian Federation (1999) Electrochemical activation: History, condition, prospects. In: Bakhira VM, pp. 36-107.

5. Shustin L, Wald H, Popovtzer MM (1998) Role of Down-Regulated CHIF mRNA in Pathophysiology of Hyperkalemia of Acute Tubular Necrosis. Am J Kidney Dis 32(4):600-4.

6. Ibishova AV, Hasanov AB, Alieva Sh E, Isaev AN (2017) Properties of ischemic, sepsis and toxic models at experiment of acute renal failure. Medical News. Pp. 14-15.

7. Bonventre JV (1993) Mechanisms of ischemic acute renal failure. Kidney Int 43(5): 1160-1178.

8. Natochin Yu V (1974) Physiology of the kidney: formulas and calculations. Pp. 60.

9. Lakin GF (1980) Biometrics. Pp. 293. 